\title{
Simulação de produção em mina subterrânea de carvão com uso de conjuntos mecanizados
}

\author{
Mining simulation for room and pillar coal operation
}

\author{
Sandro Pinzon Pereira \\ Minera San Gregório, Uruguay, MSc, \\ Eng. de Minas \\ E-mail: bulldozer1976@hotmail.com

\section{João Felipe Coimbra Leite} \\ Costa \\ LPM, UFRGS, PhD, Eng. de Minas \\ E-mail:jfelipe@ufrgs.br
}

\section{Paulo Salvadoretti}

LPM, UFRGS, Dr.Eng., Eng. de Minas E-mail: 00079207@ufrgs.br

\section{Jair Carlos Koppe}

LPM, UFRGS, PhD, Eng. de Minas E-mail:00002146@ufrgs.br

\section{Resumo}

No método de lavra câmaras-e-pilares, o sistema de lavra por conjuntos mecanizados teve, nos Estados Unidos, seu auge de aplicação entre as décadas de 50 e 60, dando lugar, posteriormente, ao sistema de mineração com minerador contínuo. No Brasil, conjuntos mecanizados ainda são utilizados em minas subterrâneas de carvão na região sul de Santa Catarina. Esse trabalho descreve um simulador de operações de lavra, onde todas as operações unitárias necessárias à extração do carvão foram incluídas. Foi desenvolvido, para a empresa Carbonífera Metropolitana S.A., um modelo computacional de simulação, que auxilia na ordenação da ocupação das frentes de lavra e nas estimativas de produção. A técnica de simulação usada denomina-se simulação por eventos discretos. Depois de construído e validado, o simulador mostrou-se eficaz na previsão de produção diária de carvão. Adicionalmente, o simulador ajuda a diagnosticar "gargalos” no ciclo de produção e esperas na realização das operações unitárias.

Palavras-chave: Lavra subterrânea, simulação de produção, carvão.

\section{Abstract}

In the room-and-pillar mining method, conventional mining system had its peak along the 1950's and 1960's in the United States, giving place to the continuous mining system. In Brazil, these systems are still in use in some underground coal mines. This paper presents a production simulator developed to emulate the mining cycle at Carbonifera Metropolitana S.A., where all the unit operations in coal mining were included. A model was proposed for the room-and-pillar mining system, aiming to maximize the extraction at all coal faces from a given panel. The technique used was discrete-event simulation. After constructed and validated, the simulator proved to be efficient to forecast daily ROM production. Added to this, the simulator is able to help in visualizing bottlenecks and operations delays in the mining cycle.

Keywords: Production simulation, continuous mining. 


\section{Introdução}

As aplicações iniciais de simulação computacional na mineração começaram nos anos 60 e deram um grande passo com os avanços da informática. Com o advento dos computadores pessoais e a disponibilidade de programas específicos, o engenheiro de minas tem tido novas ferramentas para analisar problemas de sua área (Sturgul, 2000). Rist (1961) publicou, provavelmente, o primeiro trabalho de simulação por computador. Há, relativamente, pouca literatura sobre simulação de operações em minas subterrâneas, diferentemente do que ocorre em minas a céu aberto, onde o número de trabalhos é bem maior.

No que diz respeito ao ciclo produtivo, em mina subterrânea, estudos abrangendo todas as operações de lavra deixam explícita a necessidade de se analisar um sistema em que todas as etapas estão interligadas. Fica clara a complexidade de um sistema em que nenhuma etapa deve ser estudada de forma independente, sobretudo em um local de trabalho onde se têm restrições de movimentação e vários equipamentos operando numa área, relativamente, pequena.

Dentro desse contexto, a necessidade de prever a produção e de ordenar os equipamentos no painel de lavra de uma mina subterrânea de carvão constituem-se nos objetivos principais da construção do simulador. O presente estudo descreve um modelo computacional de simulação de produção de minério no método de lavra câmaras-e-pilares, bem como sua perspectiva de utilização na otimização do emprego de equipamentos nas frentes de trabalho.

\subsection{Mina Esperança}

A Mina Esperança, onde esse estudo se desenvolveu, pertencente à Carbonífera Metropolitana S.A., está em operação desde 1984 e localiza-se no município de Treviso, Estado de Santa Catarina, distante, aproximadamente, $30 \mathrm{~km}$ de Criciúma. A mina produziu, em 2006, mais de 500.000 toneladas de carvão ROM, sendo que essa produção foi consumida, em sua maior parte, na geração de energia na Usina Termoelétrica Jorge Lacerda, localizada na cidade de Tubarão, a aproximadamente 80 km de distância. Na Mina Esperança, emprega-se o método de lavra câmaras-e-pilares, sem recuperação de pilares.

\section{Metodologia aplicada}

A metodologia aplicada, no trabalho, foi dividida nos seguintes itens:

i. Estudo detalhado das etapas e equipamentos usados na lavra.

ii. Acompanhamento do ciclo de produção nas frentes de lavra, para entendimento completo do processo.

iii. Levantamento de dados e formação de um banco de dados de tempos de serviço. iv. Construção de um simulador computacional para representar as atividades nas frentes de lavra.

v. Validação do modelo computacional de simulação.

A execução dessa metodologia é vista nos tópicos a seguir.

\subsection{0 ciclo produtivo em um painel de lavra operando com conjuntos mecanizados con- vencionais}

O sistema de produção na mina envolve as seguintes etapas:

i. Escoramento do teto.

ii. Corte da camada de carvão.

iii. Furação de frente.

iv. Desmonte com uso de explosivos.

v. Ventilacão.

vi. Limpeza (remoção do minério) da frente de lavra.

O ciclo produtivo inicia-se com o escoramento de teto, logo após a limpeza da frente de lavra. Escorado o teto, a etapa a seguir faz uso de uma cortadeira (coal cutter) para a abertura de uma face livre horizontal próxima ao piso da galeria, visando a facilitar o desmonte da camada de carvão, feito com explosivos. Executado o corte, uma perfuratriz de frente prepara a face para a colocação dos explosivos. Após isso, a frente é carregada e detonada e o minério é removido, por meio de um loader, até um shuttle-car. O shuttle-car transporta o minério fragmentado até um alimentador da correia transportadora, que encaminha a produção para a superfície. A Figura 1 ilustra o processo.

Os painéis de lavra possuem, geralmente, entre 8 e 12 galerias paralelas longitudinais de 2,3 x 6,0 metros de largura, com distâncias centro a centro variando de 17 a 24 metros.

Quanto ao número de equipamentos nos turnos, utilizamse de duas a três perfuratrizes de teto, uma cortadeira, uma perfuratriz de frente, dois loaders e três shuttle-cars. Nos painéis de lavra, há uma alocação em flancos para o trabalho dos loaders, sendo que cada loader é responsável por um dos flancos.

Atualmente, durante o avanço da lavra no painel, a distribuição dos equipamentos não segue uma sequência rígida e preestabelecida quanto à ocupação das galerias. A estratégia é priorizar o avanço frontal, atingindo logo novos cruzamentos, para disponibilizar o maior número possível de frentes de lavra (há, geralmente, entre 17 e 25 frentes disponíveis para operação). Como resultado dessa estratégia, a zona central do painel avança rapidamente, enquanto que os flancos acabam por sofrer atraso. A Figura 2 apresenta um exemplo de configuração de painel de lavra em um dos conjuntos mecanizados (CM-5), operando na empresa, conforme observado no início do primeiro turno de produção em 15/04/2004. Observam-se o maior avanço central e o arrombamento (parcial) de até quatro travessões além do alimentador de correia (AL) transportadora. 


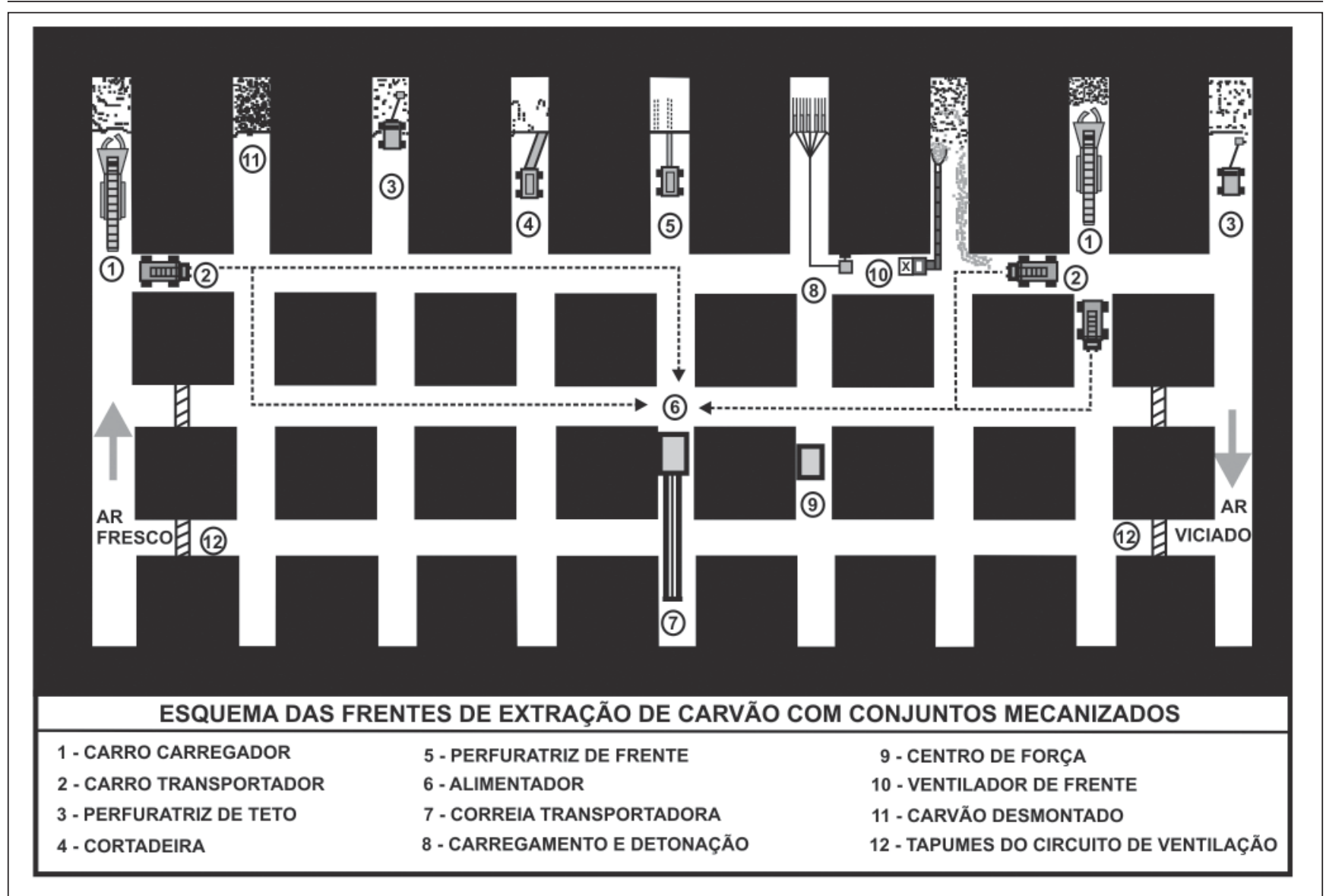

Figura 1 - Ciclo de operação de um conjunto mecanizado (adaptado de Kurcewicz, 2004).

A atividade nas frentes de lavra é executada em turnos diários de preparação e produção. No turno de preparação não há, essencialmente, limpeza (remoção) de carvão das frentes. Os loaders e shuttle-cars ficam, basicamente, inativos. O turno de preparação tem o objetivo de promover o escoramento das frentes limpas durante o turno de produção, mas que ainda não tenham sido escoradas, bem como deixar frentes desmontadas para que, no início do turno de produção, já exista carvão a ser transportado.

No turno de produção, todos os equipamentos estão ativos (ciclo completo) e a limpeza das frentes deve responder pelas frentes desmontadas e, ainda, não removidas, no turno de preparação, e, também, as desmontadas, no próprio período de produção.

O dia de trabalho pode estar organizado em um ou dois turnos de produção (de acordo com a necessidade), um turno de manutenção e outro de preparação. A capacidade de produção diária do painel varia de acordo com o regime de turnos e número de equipamentos operando.

Dentro da sistemática atual de operação dos conjuntos mecanizados, algumas características importantes podem ser observadas:
- Há dificuldade na ventilação das frentes de serviço, especialmente na parte central do painel, já que o fluxo de ar limpo, que chega por um dos flancos, tende a se deslocar na galeria imediatamente à frente do alimentador de CT.

- Há significativa variabilidade de produção entre turnos, devido, por um lado, à liberdade de escolha dada aos operadores para a alocação dos equipamentos e, por outro lado, às quebras frequentes observadas.

- Geralmente, o número de frentes disponíveis para trabalho é grande (acima de 20 frentes), porém uma política inadequada de alocação de equipamentos em um turno leva à falta de frentes disponíveis em outro.

- A distância total de deslocamento dos equipamentos durante os turnos de trabalho é maior do que seria com alocações sequenciais de ocupação das frentes.

\section{Descrição básica dos módulos do simulador}

A técnica de simulação aplicada na representação das operações de lavra com os conjuntos mecanizados denominase simulação de eventos discretos (Law \& Kelton, 1991). 


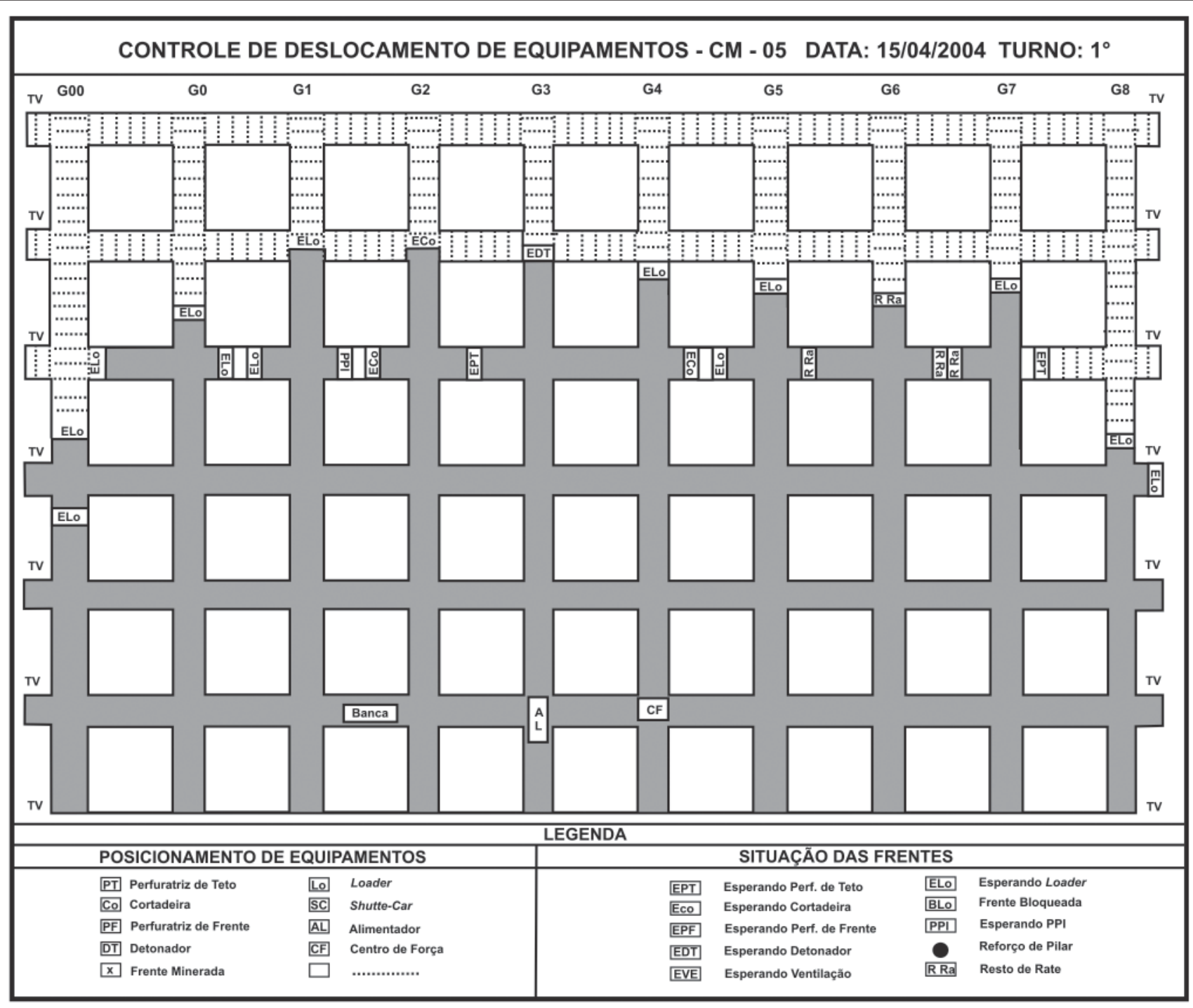

Figura 2 - Configuração das frentes de lavra no CM-5, no início do $1^{\circ}$ turno de produção, em 15/04/2004.

Modelos de simulação de eventos discretos são modelos computacionais que procuram representar o funcionamento de sistemas reais gerando uma história artificial do comportamento do sistema baseada numa lógica assumida para o modelo proposto. Resultados e observações do modelo computacional são colhidos para serem analisados, estimando-se, então, parâmetros de desempenho.

Em termos de software, o simulador de produção foi desenvolvido com base em planilhas eletrônicas Excel ${ }^{\circledR}$ usadas em conjunto com a linguagem de programação Visual Basic ${ }^{\circledR}$. Para operar o simulador, não é necessário nenhum conhecimento específico de programação. O usuário tem controle sobre a movimentação dos equipamentos e sobre a escolha de tempos específicos de realização de cada atividade, tempos definidos nas coletas de dados efetuadas na própria mina. O modelo desenvolvido se divide em 2 módulos principais. $\mathrm{O}$ módulo de posicionamento dos equipamentos, denominado módulo 1 (ver Figura 3), representa um painel esquemático de lavra no qual o usuário tem o poder de decisão para alocar os equipamentos no início de um turno de produção. Quanto à posição dos equipamentos, a escolha é livre, exigindo que o usuário tenha conhecimento do processo real, a fim de que manobras não permitidas na condução do turno não sejam executadas durante a simulação. Quanto às trocas de posição, só é permitido a cada equipamento movimentar-se para outro ponto de trabalho no momento exato indicado pelo simulador. Cada equipamento tem um comando específico, que controla toda a geração dos tempos de operação, a contagem de atividades realizadas e deixa explícito, em área selecionada, a próxima operação a ser realizada em determinada frente.

O módulo 2 - Simulador de Tempos e Movimentos divide-se em três submódulos (ver Figura 4). O primeiro submódulo, representado pela janela "Tempos Totais por Equipamento", corresponde ao somatório dos tempos de 
Sandro Pinzon Pereira et al.

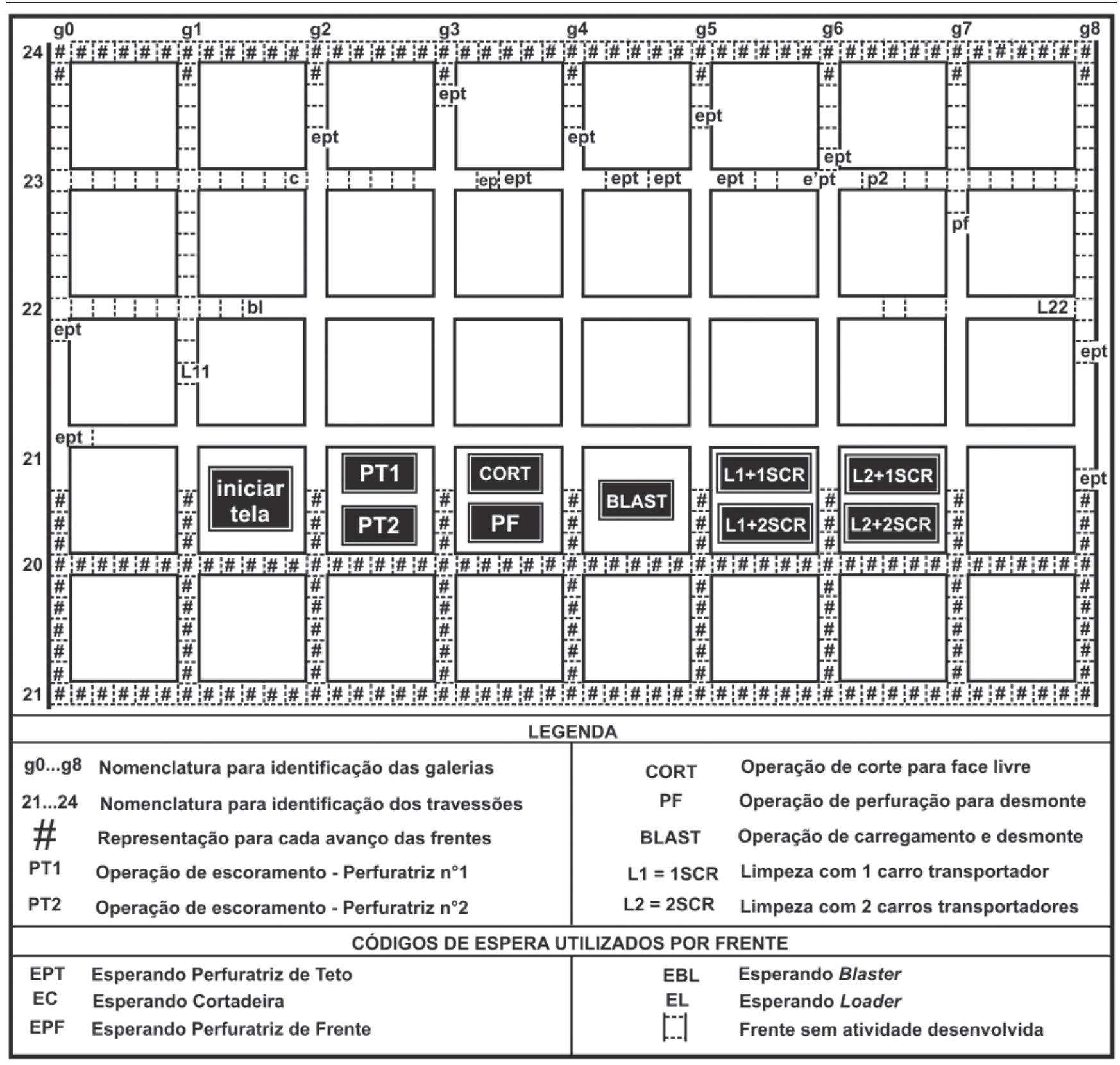

Figura 3 - Módulo 1 - Representação esquemática do painel de lavra e alocação de equipamentos.

trabalho individualizados por equipamento (A); um contador onde pode ser estipulado o tempo total de operação no turno (B) e uma janela representada por Tempos de Serviço (C), que corresponde aos tempos médios gastos pelos equipamentos na realização de cada atividade. O segundo submódulo (D) corresponde aos "Tempos de Espera por Equipamento" aguardando uma frente para desenvolver a sua atividade. O terceiro e último submódulo, identificado pela janela Contador de Frentes (E), fornece o número total de frentes em que cada equipamento desenvolveu o ciclo completo, ou seja, a produção obtida de acordo com duração estabelecida para o turno.

\section{Validação do modelo computacional de simulação}

Uma etapa essencial, na construção do simulador, é a validação, ou seja, mostrar que os dados de saída do modelo computacional são semelhantes àqueles produzidos pelo sistema real durante o funcionamento. No caso atual, a validação foi feita com respeito à produção do painel por turno de trabalho (número de frentes limpas/turno). 


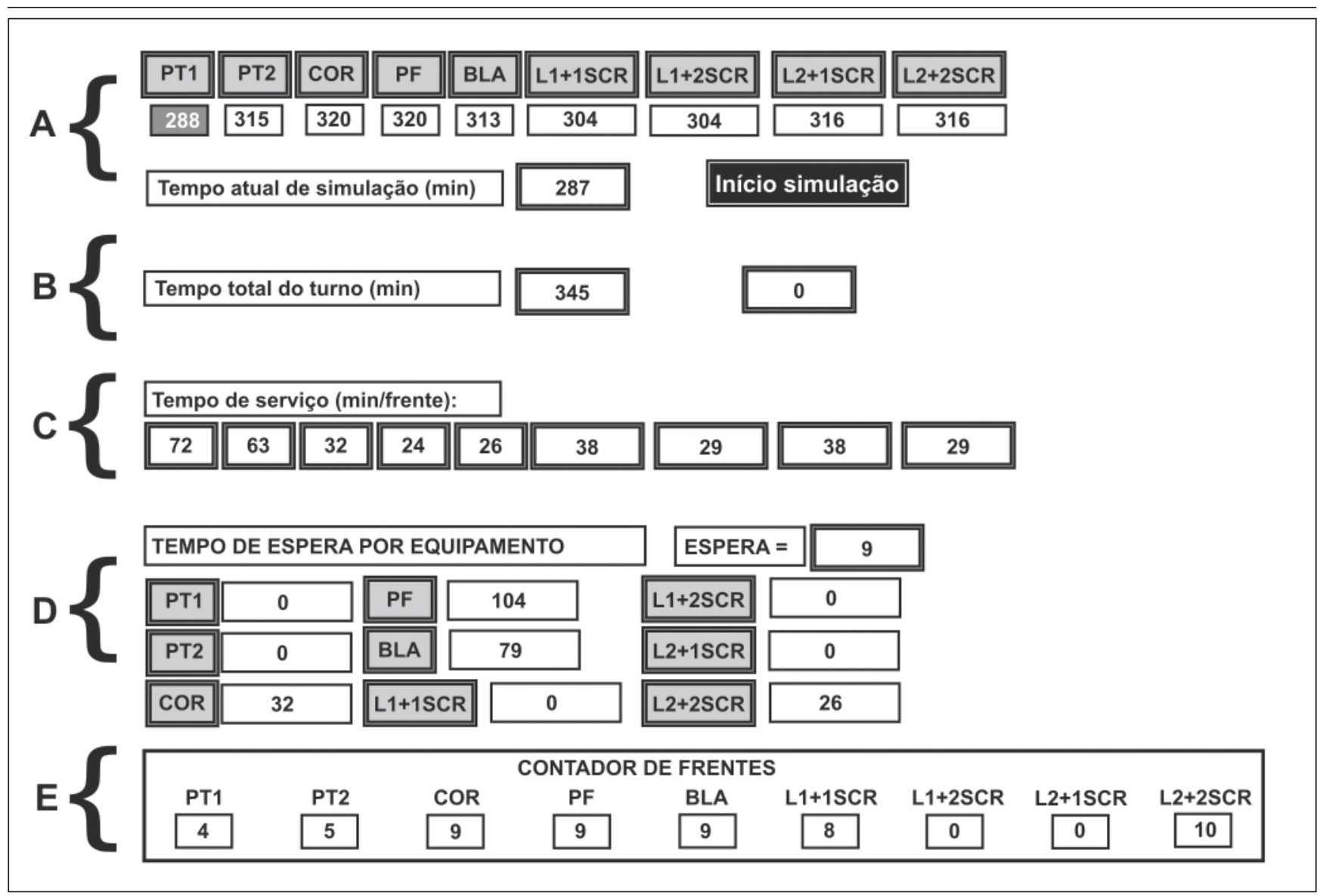

Figura 4 - Módulo 2 - Simulador de Tempos e Movimentos.

Assim, fizeram-se comparações entre as produções médias por turno obtidas pelo sistema real e as produções médias por turno obtidas pelo processo de simulação, em períodos de tempo arbitrariamente escolhidos e para determinadas configurações comuns de equipamentos atuando nos painéis. O resultado dessas comparações mostrou que a diferença entre a produção média obtida para o sistema real e para o modelo de simulação é inferior a $5 \%$. Essa pequena diferença entre sistema real e modelo de simulação permitiu concluir que o simulador produz resultados representativos do sistema real, podendo ser usado para simular alternativas de alocação de equipamentos nos painéis.

A análise comparativa de produção/turno entre sistemas real e simulado mostrou, também, que a variabilidade do sistema real é maior que a apresentada pelo modelo de simulação. Embora o ideal fosse que a simulação repetisse, também, a variabilidade do sistema real, para o parâmetro de desempenho escolhido, isto não ocorreu no presente caso. A origem desta diferença encontra-se no modo como os tempos das atividades são gerados e usados no processo de simulação. Para cada atividade, são empregados tempos médios constantes (não aleatorizados) ao longo de todo o período de simulação.
Desta forma, o modelo computacional não deve ser usado com o intuito de observar/quantificar a variância da produção média/turno. Como ocorre em outros estudos de simulação, em geral, não há necessidade de validar-se o simulador para todos os parâmetros de desempenho que podem ser obtidos do modelo computacional, apenas para os que forem designados como essenciais.

\section{Exemplo de uso do simulador}

A situação descrita a seguir ilustra uma das possibilidades de uso do simulador. Suponha-se que uma determinada ordem de ocupação das frentes, diferente do que ocorre no sistema real, deseje ser testada quanto à sua taxa de produção diária. A Figura 5 mostra a ordem escolhida para a ocupação das frentes de lavra. Em termos práticos, o painel estaria dividido em dois setores, oeste e leste, sendo utilizados dois carregadores (loaders) e duas perfuratrizes de teto, uma unidade para cada setor. Ao lavrar-se o setor leste, o primeiro trabalho de carga iniciaria em 1 , passando à frente 2 , frente 3 e, assim, sucessivamente até a frente 58 , onde o processo recomeçaria com a mesma configuração de extração. 


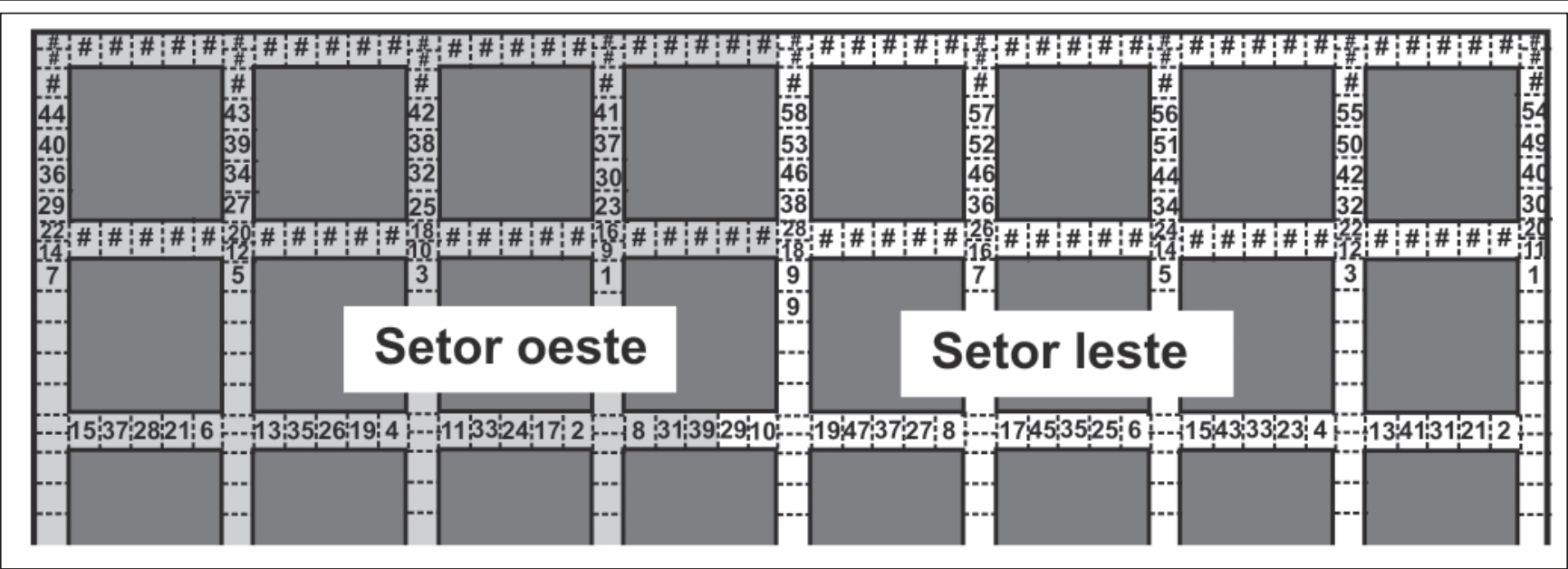

Figura 5 - Esquema mostrando a sequência de lavra das frentes (numeradas) e a divisão em setores do painel.

Simultaneamente, e de forma análoga, o setor oeste seria lavrado. O conjunto completo de equipamentos utilizados é como segue: dois loaders, três shuttlecars, duas perfuratrizes de teto, uma perfuratriz de frente, uma cortadeira de carvão e um blaster.

\section{Resultados}

Inicialmente, durante certo período de tempo, observou-se o funcionamento do sistema real e computou-se o número de frentes lavradas por dia de operação (ver Tabela 1), o que resultou em uma produção média diária de 16,2 frentes.

Posteriormente, a simulação foi efetuada considerando o modo de operação do painel de lavra referido na Figura 5. A Tabela 2 mostra o resultado da simulação, seguindo a estratégia alternativa. A simulação apresentou, para o período considerado, uma média diária de 18 frentes transportadas. A julgar pelos resultados da simulação, o emprego dessa estratégia de uso dos equipamentos eventualmente poderia gerar ganhos na escala de produção, mas é preciso comparar resultados levando-se em conta que os dados coletados no sistema real apresentam aleatoriedade (a produção diária é uma variável aleatória).

Tabela 1 - Frentes limpas por dia de produção na situação real.

\begin{tabular}{c|c|c|c|c|c|c|c|c}
\hline 18 & 15 & 17 & 17 & 18 & 17 & 10 & 10 & 9 \\
\hline 17 & 18 & 16 & 16 & 16 & 15 & 19 & 18 & 17 \\
\hline 19 & 20 & 14 & 20 & & & & & \\
\hline
\end{tabular}

Tabela 2 - Frentes limpas em cada dia na situação simulada.

\begin{tabular}{c|c|c|c|c|c|c|c|c}
\hline 17 & 19 & 20 & 20 & 16 & 17 & 16 & 20 & 20 \\
\hline 20 & 17 & 16 & 15 & 20 & 19 & 19 & 20 & 16 \\
\hline 17 & 17 & 19 & 19 & 18 & 18 & 15 & 17 & 20 \\
\hline
\end{tabular}

\section{Discussão de resultados}

Uma forma para comparar resultados de simulação entre si ou em relação a um sistema real, quando há variáveis aleatórias envolvidas, é formando o intervalo de confiança para a diferença entre médias de desempenho dos dois sistemas (Law \& Kelton, 1991). Esse é um recurso utilizado quando se deseja inferir se as médias de duas populações diferem ou não entre si estatisticamente, para um dado nível de significância.

A comparação é realizada a partir do intervalo de confiança para a diferença entre médias dos sistemas. Se o intervalo de confiança contém o valor zero, o comportamento médio dos dois sistemas não difere significativamente.
Suponha-se que $X_{i l}, X_{i 2}, \ldots, X_{i n}$, são $n$ realizações independentes e identicamente distribuídas (IID) do sistema i, para $i=1,2$ (no presente caso, $i=1$ é o sistema real e $i=2$ são os resultados de simulação), e $\mu_{i}=E\left(X_{i j}\right)$ é o parâmetro de interesse, ou seja, a média das observações $X_{i j}$ do sistema $i$, onde $j=1$, 2, $\ldots, n$. Deseja-se construir um intervalo de confiança para $\zeta=\mu_{1}-\mu_{2}$ (diferença entre médias dos dois sistemas).

Na comparação, usam-se n observações do sistema 1 e 2, mesmo que se tenha de descartar alguns dados de um dos sistemas. Deve-se parear os valores $X_{1 j}$ e $X_{2 j}$ para definir $Z_{j}=X_{l j}-X_{2 j}$. Os valores $Z_{j}$ são realizações $I I D$ e $E(Z)=\zeta$ é a quantidade para a qual querse construir o intervalo de confiança. Dessa forma, tem-se: 
$z(n)=\frac{\sum_{j=1}^{n} Z j}{n}$

$$
\operatorname{Var}[z(n)]=\frac{\sum_{\mathrm{j}=1}^{\mathrm{n}}[\mathrm{Zj}-\mathrm{z}(\mathrm{n})]^{2}}{\mathrm{n}(\mathrm{n}-1)}
$$

$\mathrm{z}(\mathrm{n}) \pm \mathbf{t}_{\mathrm{n}-\mathbf{1}, \mathbf{1 - \alpha} / \mathbf{2}} \sqrt{\operatorname{Var}[z(n)]}$

A expressão (3) apresenta o intervalo de confiança para $\zeta$, onde $z(n)$ é a média das diferenças e $t_{n-1}{ }_{1-\alpha / 2}$ são valores críticos da distribuição t.

Se os valores $Z_{j}$ são, normalmente, distribuídos, esse intervalo é exato e com probabilidade 1- $\alpha$. O intervalo de confiança é denominado de intervalo de confiança t-pareado. Nessa abordagem, é importante dizer que $\mathrm{X}_{1 j}$ e $X_{2 j}$ não necessitam de ser independentes e que as variâncias $\operatorname{Var}\left(X_{1 j}\right)$ e $\operatorname{Var}\left(X_{2 j}\right)$ não precisam de ser iguais.

A Tabela 3 compara o número de frentes limpas por dia na situação real com os valores simulados.

Aplicando o método de comparação (assume-se que as realizações $X_{1 j}$ são IID, o mesmo ocorrendo com os valores $X_{2 j}$ ), o valor médio $z(n)$, para as diferenças, foi de -1,95 e a variância $\operatorname{Var}[z(n)]$ foi de 0,65. Para 90\% de confiança e $n=22$ (foram descartados 4 dados de produção simulada), uma tabela da distribuição $t$ fornece $t_{21,95 \%}=$ 1,721. Assim, o intervalo de confiança é: $-1,95 \pm 1,721 \sqrt{0,65}=\{-3,33 ;-0,57\}$

O intervalo de confiança não contém o valor zero, por isso conclui-se que o comportamento médio do sistema real e o da configuração simulada diferem significativamente, isto é, o nível de produção médio simulado, conforme as restrições dadas, pode ser considerado
Tabela 3 - Comparação entre produção diária real e simulada.

\begin{tabular}{|c|c|c|}
\hline $\begin{array}{l}\text { Produção real } X_{1 j} \\
\text { (frentes/dia) }\end{array}$ & $\begin{array}{l}\text { Produção simulada } \\
X_{2 \mathrm{j}} \text { (frentes/dia) }\end{array}$ & $\begin{array}{r}\text { Diferença } Z_{j} \\
\text { (frentes/dia) }\end{array}$ \\
\hline 18 & 17 & 1 \\
\hline 15 & 19 & -4 \\
\hline 17 & 20 & -3 \\
\hline 17 & 20 & -3 \\
\hline 18 & 16 & 2 \\
\hline 17 & 17 & 0 \\
\hline 10 & 16 & -6 \\
\hline 10 & 20 & -10 \\
\hline 9 & 20 & -11 \\
\hline 17 & 20 & -3 \\
\hline 18 & 17 & 1 \\
\hline 16 & 16 & 0 \\
\hline 16 & 15 & 1 \\
\hline 16 & 20 & -4 \\
\hline 15 & 19 & -4 \\
\hline 19 & 19 & 0 \\
\hline 18 & 20 & -2 \\
\hline 17 & 16 & 1 \\
\hline 19 & 17 & 2 \\
\hline 20 & 17 & 3 \\
\hline 14 & 19 & -5 \\
\hline 20 & 19 & 1 \\
\hline
\end{tabular}

estatisticamente maior (em média 1,95 frentes/dia) que o do sistema real, para um nível de confiança de $90 \%$.

\section{Conclusão}

Sob o ponto de vista de concepção e desenvolvimento do simulador, os objetivos foram atingidos. Tarefas básicas e com grande consumo de tempo, como as coletas de dados de tempos de operação por atividade, foram cumpridas e proporcionaram a experiência necessária à equipe de trabalho para a idealização da ferramenta computacional, além de um conhecimento mais íntimo de todo o processo produtivo. A própria análise do banco de dados forneceu os elementos necessários para a identificação de vários pontos problemáticos em termos de operação e dos “gargalos” de produção.

O sistema computacional mostrou comportamento satisfatório, dentro da proposta de gerar estimativas de produção por turno de trabalho.

Quanto à futura utilização do software, vislumbram-se algumas aplicações para as quais o programa revela-se potencialmente importante: 
i. Treinamento de pessoal de operação (pela destacada capacidade de visualização das operações de painel que ele proporciona).

ii. Análise de configurações (quantidade e organização) de equipamentos.

iii. Previsão dos reflexos no encadeamento de turnos de trabalho com funções diferentes (preparação x produção).

iv. Melhor visualização da interação física entre equipamentos próximos ou juntos aos locais de detonação (a proximidade limita a atuação dos equipamentos).

v. Funcionar como ferramenta de suporte para o planejamento operacional e de produção.

\section{Referências bibliográficas}

KURCEWICZ, J.A. Desmonte com explosivo em lavra subterrânea de carvão: avaliação do desempenho e utilização de ANFO. Universidade Federal do Rio Grande do Sul, Programa de PósGraduação em Engenharia de Minas, Metalúrgica e de Materiais (PPGEM), 2004. 146p. (Dissertação de Mestrado).

LAW, A. M., KELTON, W. D. Simulation Modeling and Analysis. (2nd. Ed.). Singapore: McGraw-Hill, 1991. 759p.

RIST, K. The solution of a transportation problem by use of Monte Carlo Technique. APCOM 1. Tucton: University of Arizona, March. 1961.

STURGUL, J.R. Mine Design: Examples Using Simulation, Society for Mining, Metallurgy and Exploration, Inc. SME, Littleton, CO p.13-31. 2000.

Artigo recebido em 06/04/2009 e aprovado em 25/05/2009.

\section{Descubra as muitas informações da: Geologia, Mineração, Metalurgia \& Materiais e Engenharia Civil.}

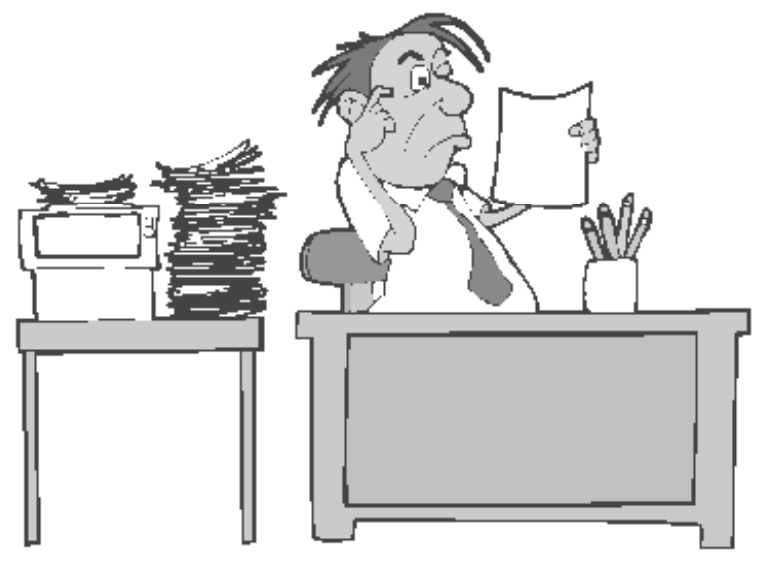

\section{Assine e publique na Rem}

Conheça o nosso site: WWW.rem.com.br 